\title{
Study and Design a Novel Adaptive Array Antenna for a RFID Applications
}

\author{
A.Bendali ${ }^{1}$, S. Bri ${ }^{2}$, M. Habibi ${ }^{3}$, M.N. Srifi ${ }^{4}$, A. El fellahin ${ }^{5}$ \\ ${ }^{1,3}$ Laboratory of Electrical Engineering and Energy Systems, Faculty of Sciences, Ibn tofail, Morocco, \\ abdelhak.bendali@hotmail.com, mohamed.habibi@hotmail.com \\ ${ }^{2}$ Materials and Instrumentations group, High School of Technology, Moulay Ismail University, Morocco \\ briseddik@gmail.com \\ ${ }^{4}$ Electronics and Telecommunication Systems Research Unit, National School of Applied Sciences, Ibn Tofail \\ University, Morocco, srifimn@ gmail.com \\ ${ }^{5}$ SATIE, UMR CNRS 8029, ENS Cachan, Univ. Paris Saclay, Cachan, France \\ abdelhatif.elfellahi@gmail.com
}

\begin{abstract}
In this paper, a novel structure of antenna array which compose of $\mathrm{H}$-shaped patch antennas with slot and parasitic elements has been presented and discussed. The proposed antenna is suitable for RFID (Radio Frequency Identification) applications. It is dedicated to operate in the frequency band centered on the resonance frequency $\mathrm{f}_{0}=$ $2.45 \mathrm{GHz}$. It is fed by a parallel linear array adapted to $50 \Omega$. High Frequency Structural Simulator (HFSS) software is used to optimize geometric parameters and simulate the radiation characteristics of the proposed antenna array. The simulation results show that the reflection coefficient reaches a level of at least $-31 \mathrm{~dB}$ at the operating frequency of the antenna, a narrow bandwidth of the order of $26 \mathrm{MHz}$, and a gain of $6.6 \mathrm{~dB}$.
\end{abstract}

Key words: RFID array antenna, adaptation, Return loss, Radiation Diagram, HFSS Simulator

\section{INTRODUCTION}

Radio frequency identification is an electronic tagging technology that allows an object, a place Radio frequency identification is an electronic tagging technology that authorizes an object, a place or a living being to be identified using a radio wave exchange [1]. This technology has the distinction of operating remotely according to the principle that a reader sends a radio signal and receives in return the responses of the labels that are in its field of action.

The radiation pattern of a base element is relatively broad and provides low values of directivity and gain. So, to overcome the problem of long-distance communication, it is necessary to design antennas with very directive characteristics and very high gains. This cannot be accomplished by a single elemental antenna.

Network antennas consist of a set of identical elementary sources fed by separate channels [2]. These sources are often dipoles, cornets or printed elements. This regular association of identical antennas has the objective of creating radiation of particular shape and directing the radiated power to a desired angular sector. The radiated power is, therefore, greater because we multiply the number of radiating elements (network factor). The radiation results from the inphase addition of fields from each radiating element [3] and dielectric resonator [4].

The power supply controls the amplitudes and relative phases of these sources and creates the type of linear or flat array antenna [5], [6]. There are two ways to power a linear array, either in series [7] or parallel [8]-[10].

In this part, we consider a parasitic element patch-H antenna fed by a microstrip line at $2.45 \mathrm{GHz}$. The proposed planar antenna is used in a linear array of four equally spaced elements for a UHF RFID application. The proposed antenna array is shaped on an epoxy type FR4 substrate of thickness $1.6 \mathrm{~mm}$ and relative permittivity 4.4. The results obtained for the reflection coefficient, the standing wave ratio, and the radiation pattern are presented and discussed.

\section{DESIGN AND CONFIGURATION OF THE ANTENNA ARRAY}

\subsection{Elementary Antenna Structure}

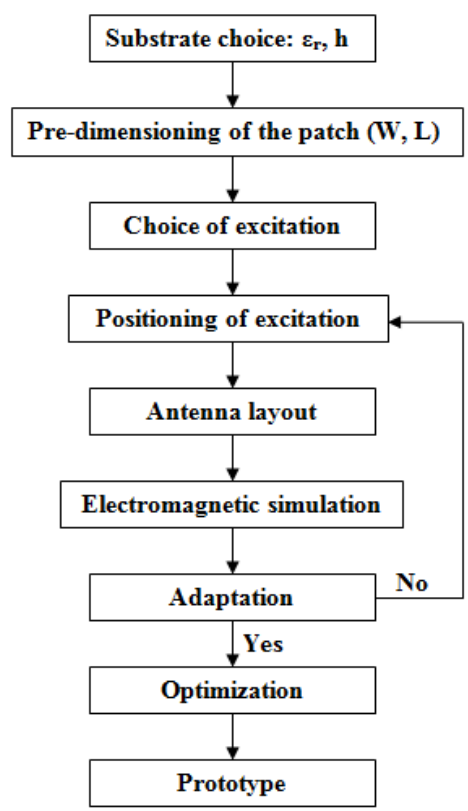


Figure 1: Organization chart of a patch antenna

The design methodology of the patch antenna that we adopted is based on the insertion of the notches at the level of the radiating element in order to improve its performance in terms of adaptation and radiation pattern around a frequency of resonance of $2.45 \mathrm{GHz}$ (Figure 1).

The architecture of the proposed patch- $\mathrm{H}$ antenna is given in Figure 2. For a better impedance matching, a simple rectangular slot is introduced on the patch and makes it possible to increase the effective surface area of the antenna. An FR4 epoxy substrate having a height $\mathrm{h}=1.6 \mathrm{~mm}$, a relative dielectric constant $\varepsilon r$ equal to 4.4 and a loss tangent of 0.02 is used for the design. We note that our elementary antenna is excited by an axial microstrip line. The patch was modeled under HFSS Studio and its dimensions were adjusted in resonance at $2.45 \mathrm{GHz}$. The optimized dimensions geometrics of the patch are given in Table 1.

Table 1: $\quad$ The size of the base antenna

\begin{tabular}{|c|c|}
\hline Parameters & Values (mm) \\
\hline $\mathrm{W}_{\mathrm{g}}$ & 46 \\
\hline $\mathrm{L}_{\mathrm{g}}$ & 51 \\
\hline $\mathrm{L}$ & 20 \\
\hline $\mathrm{W}$ & 34 \\
\hline $\mathrm{a}$ & 12 \\
\hline $\mathrm{b}$ & 1 \\
\hline $\mathrm{c}$ & 3 \\
\hline $\mathrm{e}$ & 3 \\
\hline $\mathrm{f}$ & 5 \\
\hline $\mathrm{d}$ & 10 \\
\hline $\mathrm{Y}_{0}$ & 11 \\
\hline $\mathrm{h}$ & 11.5 \\
\hline $\mathrm{i}$ & 1 \\
\hline $\mathrm{g}$ & 6.4 \\
\hline $\mathrm{k}$ & 13 \\
\hline $\mathrm{n}$ & 2.6 \\
\hline $\mathrm{m}$ & 21 \\
\hline
\end{tabular}

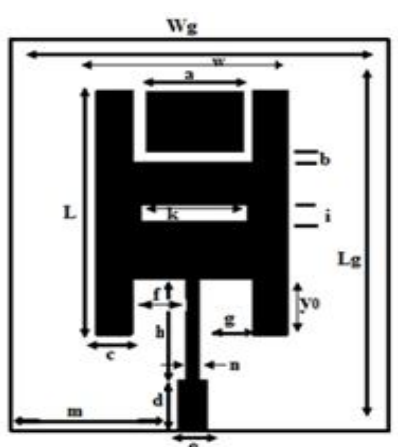

(a)

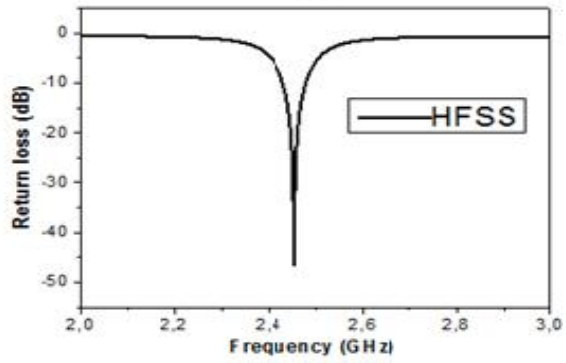

(b)
Figure 2: Base element of the network antenna: (a) topology, (b) reflection coefficient

Figure 2 (a) and (b) show the topology and reflection coefficient of the elemental patch antenna. It can clearly be seen that the antenna resonates at $2.45 \mathrm{GHz}$ and has a bandwidth of $42 \mathrm{MHz}$ to $-10 \mathrm{~dB}$.

\subsection{Structure of the Proposed Network Antenna}

Linear arrays are the simplest networks [8], [11]. We consider a linear network consisting of $\mathrm{N}$ elements (or sources) arranged along the $\mathrm{x}$ or $\mathrm{y}$ axis. The inter-element distance $\mathrm{d}$ is assumed to be constant although it is possible to make networks with a variable inter-element distance (Figure 3 ). Each source is represented by a power amplitude noted $a_{n}$ and a phase shift $\phi_{n}$.

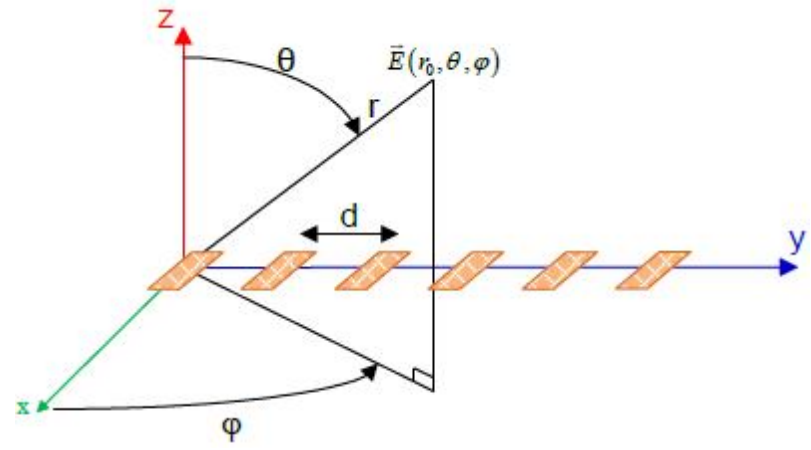

Figure 3: Generic diagram of a linear array of antennas [12]

To simplify the calculations, it is essential to eliminate electromagnetic coupling between the sources and the radiating elements. According to the superposition theorem, the total field radiated by $\mathrm{N}$ elements at a point $\mathrm{M}$, considered at great distance, is equal to the vector sum of the fields emitted by each source [13].

The total field radiated in the extreme zone of a onedimensional network is the sum of the different contributions radiated by each element:

$\mathrm{E}_{\mathrm{t}}(\theta, \varphi)=\sum_{\mathrm{n}=0}^{\mathrm{N}-1} \mathrm{E}_{\mathrm{n}}(\theta, \varphi)=\mathrm{A} \sum_{\mathrm{n}=0}^{\mathrm{N}-1} \mathrm{a}_{\mathrm{n}} \frac{\mathrm{e}^{-\mathrm{jkr} \mathrm{n}}}{\mathrm{r}_{\mathrm{n}}} \mathrm{e}^{-\mathrm{j} \phi_{\mathrm{n}}} \mathrm{f}_{\mathrm{n}}(\theta, \varphi)$

Where $f_{\mathrm{n}}(\theta, \varphi)$ is the characteristic function of the element $\mathrm{n}$ of the network, $\mathrm{A}$ is a constant and $\phi_{\mathrm{n}}$ is the electronic phase of the source $n$.

In the case of the far-field approximation, the distances $r_{i}$ are very little different from each other and this difference in the amplitude term can be neglected. On the other hand, the term which intervenes in the variation of the phase is not negligible and is written [14]:

$$
r_{1} \approx r_{i}+n d \sin (\theta)
$$

with $d \cdot \sin (\theta)$ the difference between two successive elements distant from $d$.

We deduce that the total field radiated by a network of $\mathrm{N}$ identical and equidistant sources is:

$$
\mathrm{E}_{\mathrm{t}}(\theta, \varphi)=\mathrm{A} \frac{\mathrm{e}^{-\mathrm{jkr} \mathrm{r}_{0}}}{\mathrm{r}_{0}} \mathrm{~F}(\theta, \varphi) \sum_{\mathrm{n}=0}^{\mathrm{N}-1} \mathrm{a}_{\mathrm{n}} \mathrm{e}^{-\mathrm{j}\left(\mathrm{nd} \sin (\theta) \mathrm{kr}_{\mathrm{n}}+\phi_{\mathrm{n}}\right)}
$$


Total radiation is the radiation of a radiating element multiplied by the network factor and is expressed by the following formula:

$$
\mathrm{E}_{\mathrm{t}}(\theta, \varphi)=\mathrm{A} \frac{\mathrm{e}^{-\mathrm{jkr} \mathrm{r}_{0}}}{\mathrm{r}_{0}} \mathrm{~F}(\theta, \varphi) \mathrm{AF}
$$

The term AF represents the contribution of the network to the radiation of the antenna. It is given by the following relation [15]:

$$
\mathrm{AF}=\sum_{\mathrm{n}=0}^{\mathrm{N}-1} \mathrm{a}_{\mathrm{n}} \mathrm{e}^{-\mathrm{j}\left(\mathrm{nd} \sin (\theta) \mathrm{kr}_{\mathrm{n}}+\phi_{\mathrm{n}}\right)}
$$

\section{A. Linear antenna array $1 \times 2$}

The Figure 4 shows the geometry of an optimized $1 \times 2$ network antenna element. The popular simple power divider having a characteristic impedance input of $50 \Omega$ has been used to drive the two-element array antenna. Impedance matching depends on the dimensions of the power divider.

The simulation of the evolution of the reflection coefficient obtained through the simulation software HFSS of the linear antenna1 $\times 2$ is given in Figure 5 (a). The results obtained show that the $S_{11}$ is in the order of $-30 \mathrm{~dB}$ at the operating frequency $\mathrm{f}_{0}=2.45 \mathrm{GHz}$.

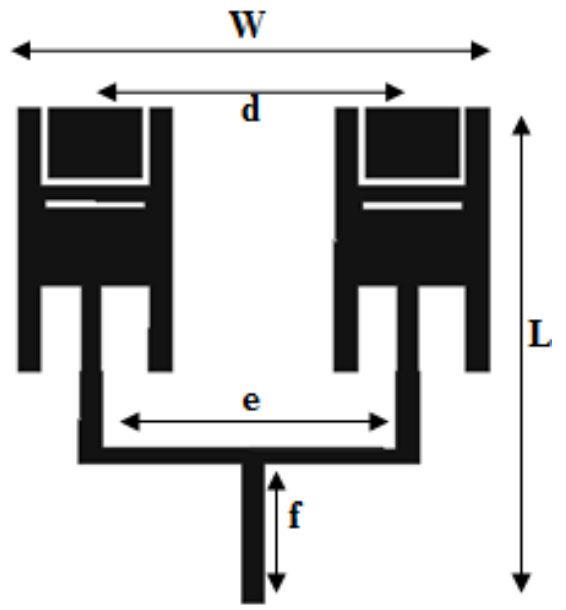

Figure 4: Geometry of the $1 \times 2$ network antenna: $\mathrm{W}=$ $61 \mathrm{~mm} ; \mathrm{L}=64 \mathrm{~mm} ; \mathrm{d}=21 \mathrm{~mm} ; \mathrm{e}=34 \mathrm{~mm} ; \mathrm{f}=18 \mathrm{~mm}$

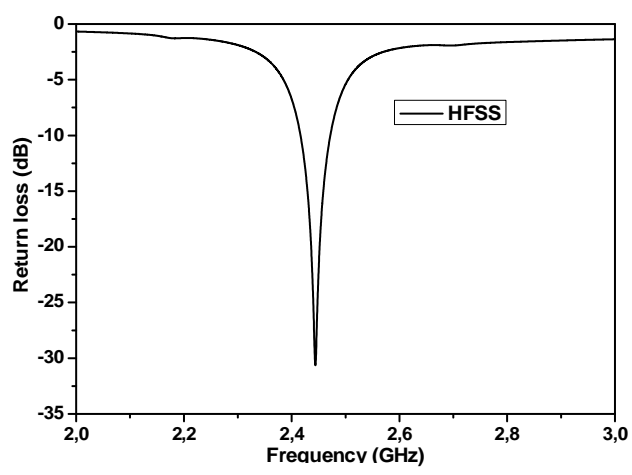

(a)

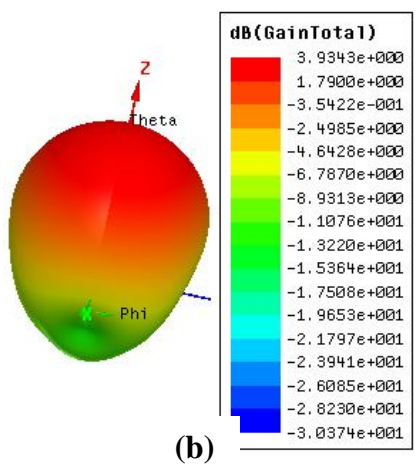

Figure 5: Radiation characteristics of the array antenna 1 $\times 2$ : (a) Return loss, (b) Radiation pattern

In the second part, we are interested in analyzing and improving the radiation characteristics of an identical fourelement patch antenna array using the same optimized patch element in the first part of this work.

\section{B. Planer antennas array $2 \times 2$}
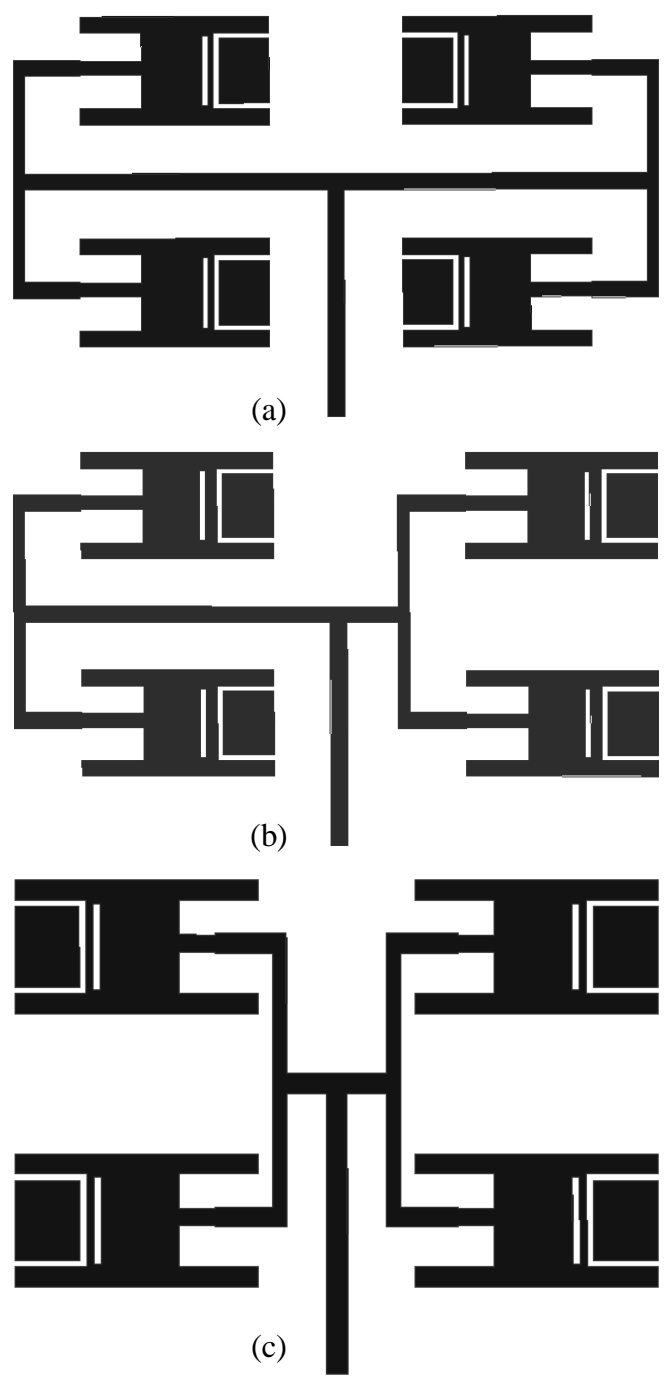

Figure 6: Different topology of the network antenna $2 \times 2$ 


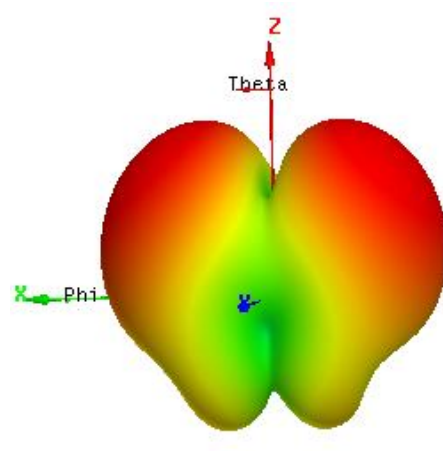

(e)
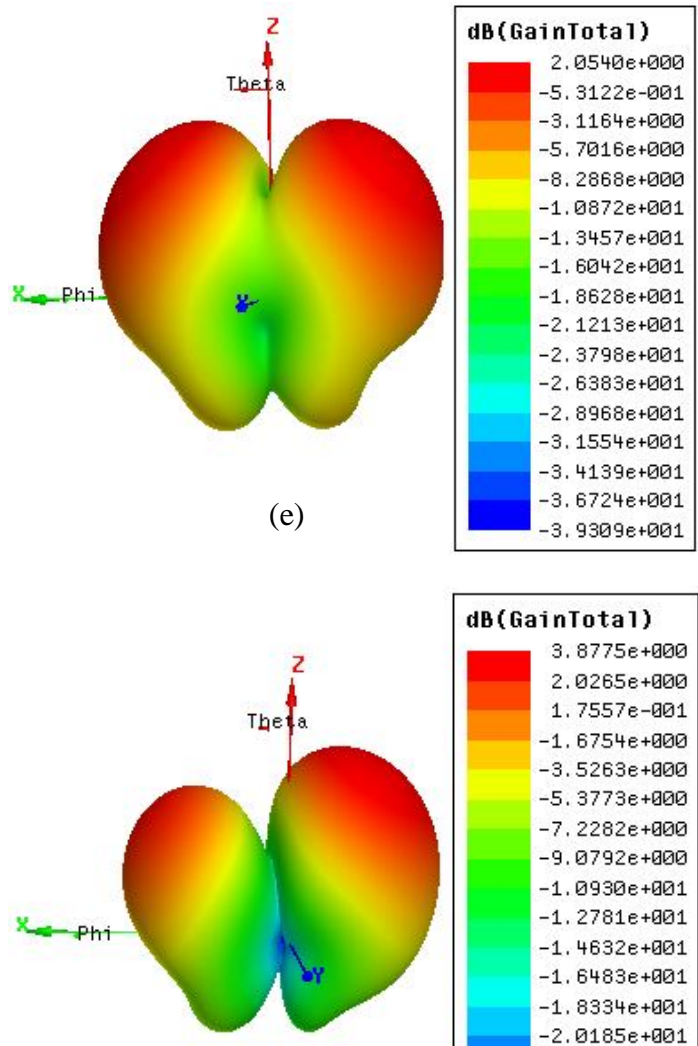

(f)
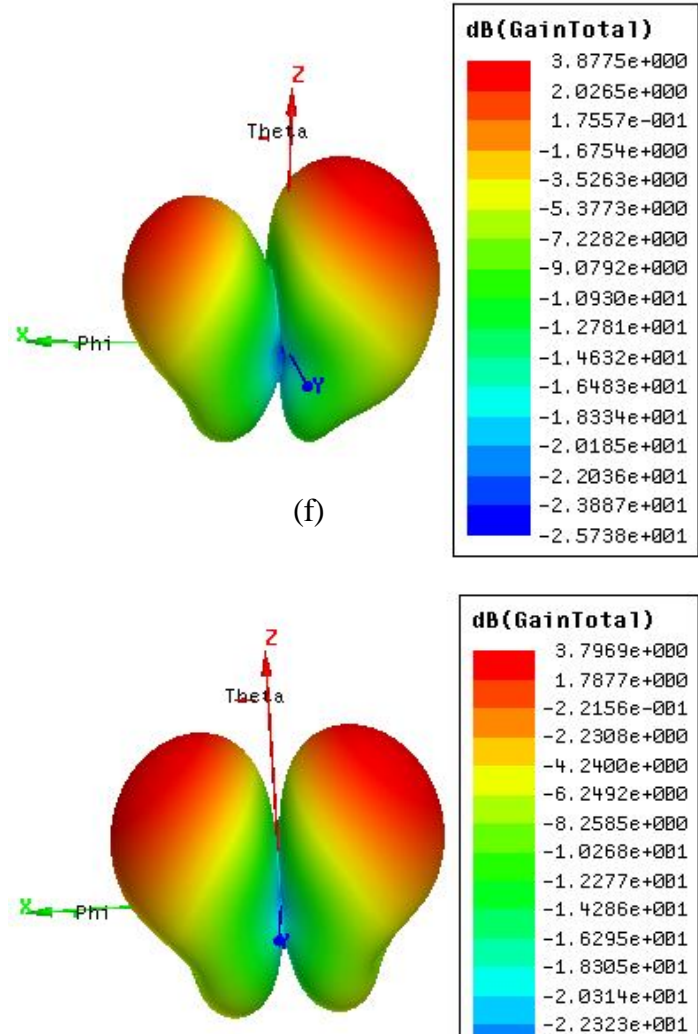

(g)

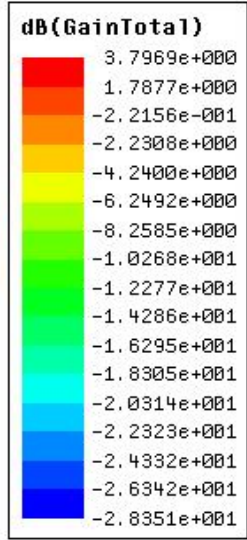

Figure 7: Radiation characteristics of the array antenna $2 \times 2$ : (e) for the toplogie (a), (f) for the topologie (b), (g) for the toplogie (c)

Figure 6 and Figure 7 successively represent the different network antenna topologies $2 \times 2$ and their radiation characteristics. Simple T-form power dividers with a characteristic $50 \Omega$ impedance input are used to power the four elements of the network antenna. The results obtained show that the radiation pattern of the different topologies represents two main lobes with a low gain.

\section{Linear antennas array $1 \times 4$}

Figure 8 shows the geometry of an optimized $1 \times 4$ network antenna element. Three popular simple power dividers with a characteristic $50 \Omega$ impedance input are used to drive the four elements of the network antenna. Impedance matching depends on the dimensions of the power splitters. It should be noted that the improvement of the adaptation and the distance between the elements of the network antenna makes it possible to improve the performances of the radiations by improving particularly the bandwidth and the gain.

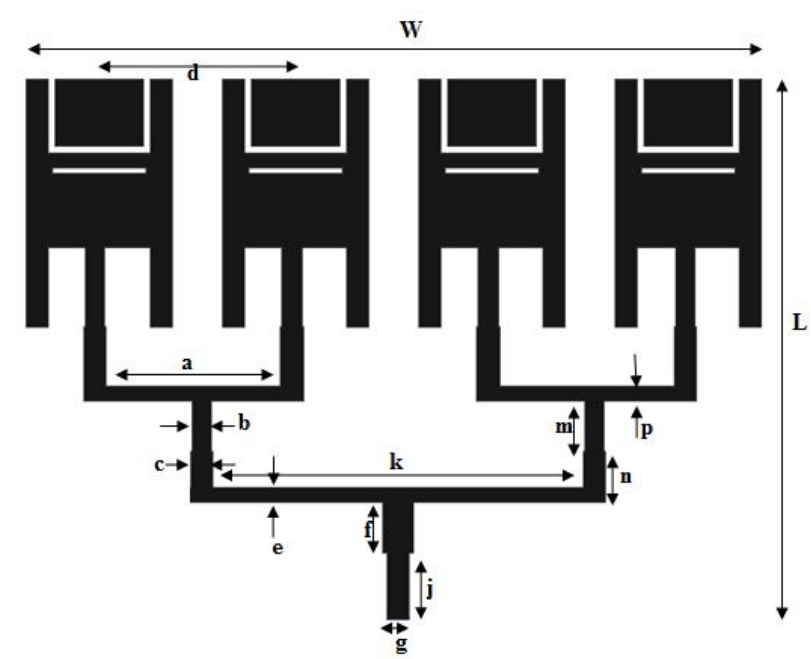

Figure 8: Topology of the network antenna $1 \times 4: \mathrm{W}=$ $161 \mathrm{~mm} ; \mathrm{L}=94 \mathrm{~mm} ; \mathrm{a}=44 \mathrm{~mm} ; \mathrm{b}=2.6 \mathrm{~mm} ; \mathrm{c}=3 \mathrm{~mm}$; $\mathrm{d}=47 \mathrm{~mm} ; \mathrm{e}=2 \mathrm{~mm} ; \mathrm{f}=15 \mathrm{~mm} ; \mathrm{j}=13 \mathrm{~mm} ; \mathrm{g}=2 \mathrm{~mm}$; $\mathrm{k}=91 \mathrm{~mm} ; \mathrm{m}=11 \mathrm{~mm} ; \mathrm{n}=9 \mathrm{~mm} ; \mathrm{p}=2 \mathrm{~mm}$

The simulation results obtained for the linear array antenna with four identical elements in terms of reflection coefficient are confirmed by 3D software CST, and good results are observed (Figure 9). Simulated standing wave ratio and gain in a frequency range between $2 \mathrm{GHz}$ to $3 \mathrm{GHz}$ are respectively presented in Figure 10 and 11. The results show that the reflection coefficient reaches a value of the order of $30 \mathrm{~dB}$ at the operating frequency with a range of $29 \mathrm{MHz}$, the standing wave ratio is of the order of 1.06 and the gain reaches a value of $6.6 \mathrm{~dB}$.

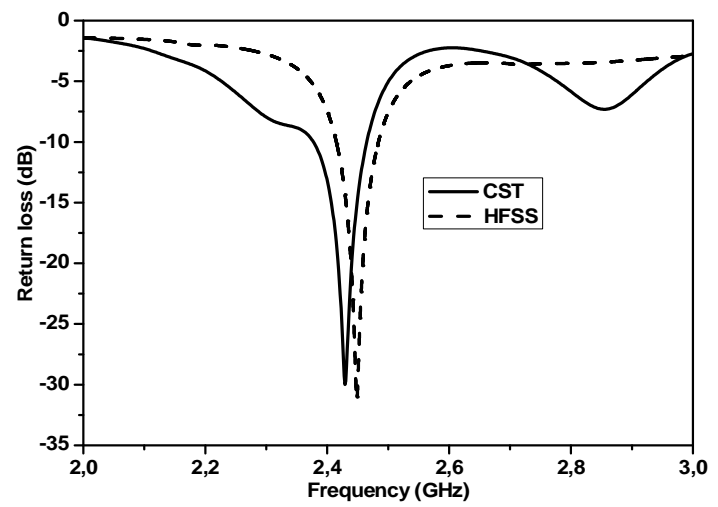

Figure 9: $\quad$ Simulated $S_{11}$ parameters

The comparison of the simulation results of the reflection coefficient obtained by the simulation software HFSS and CST of the antenna are presented in Fig.9. The simulation results obtained with the two simulation computer software show a good agreement. As we can be seen, our antenna works very well in the desired frequency $\mathrm{f}_{0}=2.45 \mathrm{GHz}$ with a bandwidth of $66 \mathrm{MHz}$. 
A.Bendali et al., International Journal of Emerging Trends in Engineering Research, 7(12), December 2019,805 - 811

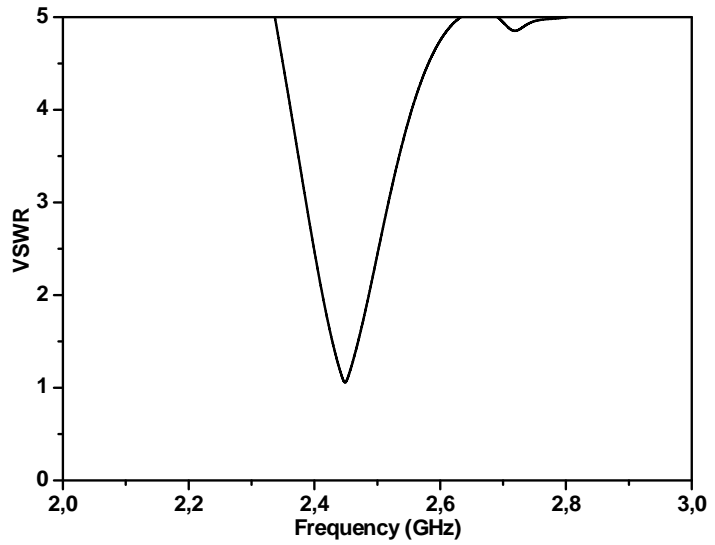

Figure 10: Standing wave rate as a function of frequency

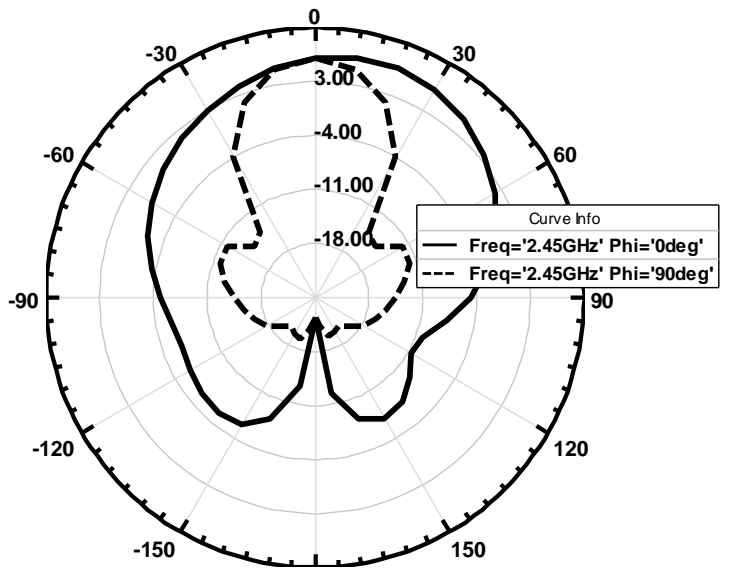

(a)

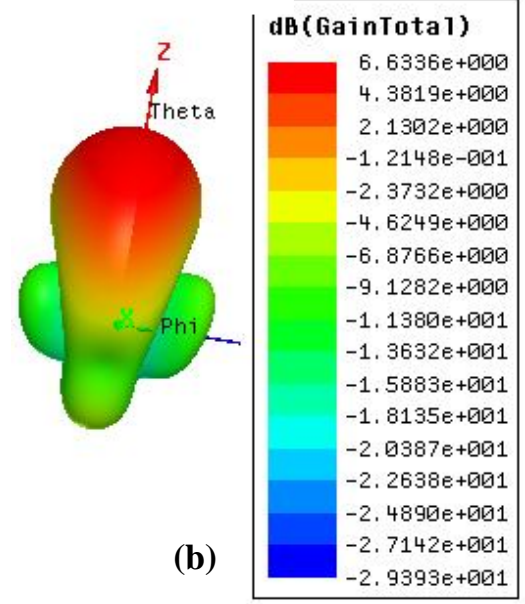

Figure 11: 2 and $3 \mathrm{D}$ radiation pattern at $\mathrm{f}=2.45 \mathrm{Ghz}$

Table 2 shows the comparison of this work with other published works. The antenna feed network proposed remains identical to that presented in both literature with an improvement in size compared to that presented in [8] and a slight improvement of the gain compared to that presented in [7].
Table 2: Comparison of the proposed work with published array antenna

\begin{tabular}{|c|c|c|c|}
\hline Parameters & Ref [8] & Ref [7] & $\begin{array}{c}\text { This } \\
\text { work }\end{array}$ \\
\hline Antenna array & $1 \times 4$ & $1 \times 4$ & $1 \times 4$ \\
\hline $\begin{array}{c}\text { Resonant } \\
\text { frequency } \\
\text { (GHz) }\end{array}$ & 2.4 & 2.26 & 2.45 \\
\hline $\begin{array}{c}\text { Antenna } \\
\text { footprint } \\
\text { (mm })\end{array}$ & $252 \times 100$ & $53.93 \times 91.62$ & $161 \times 91$ \\
\hline $\begin{array}{c}\text { Relative } \\
\text { bandwidth (\%) }\end{array}$ & - & 10.18 & 2.8 \\
\hline Gain (dBi) & 14.5 & 5.10 & 6.6 \\
\hline Efficiency (\%) & 95.66 & - & 60 \\
\hline S $\mathbf{1 1}(\mathbf{d B})$ & -39 & -21.5 & -30 \\
\hline
\end{tabular}

D. Influence of inter-element distance on the radiation pattern

We have seen that the networking of collinear antennas led to the creation of a high gain main lobe, whose direction could be modified by the excitation phase of each antenna. Unfortunately, high-gain side lobes are also generated in different directions. These side lobes reduce the gain of the main lobe and generate parasitic radiation in directions where the antenna should not radiate (Figure 12).

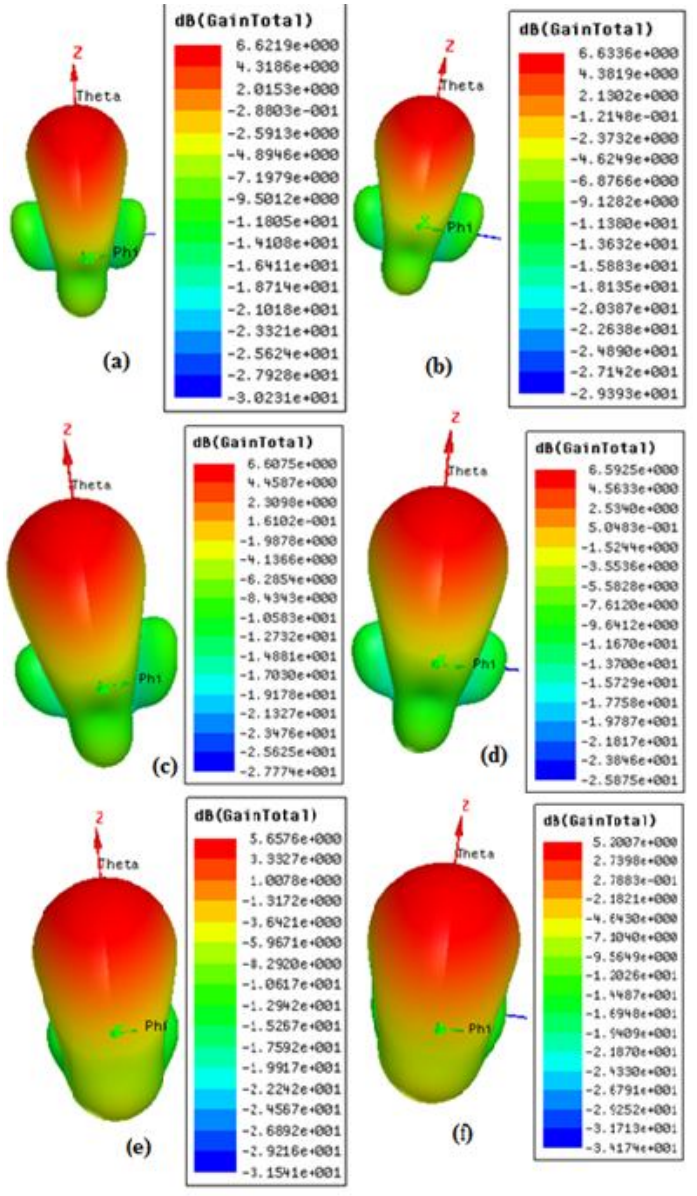

Figure 12: Radiation patterns as a function of interelement distance: (a) $d=47 \mathrm{~mm}$, (b) $d=45 \mathrm{~mm}$, (c) $d=43 \mathrm{~mm}$, (d) $d=31 \mathrm{~mm}$, (e) $d=29 \mathrm{~mm}$, (f) $d=27 \mathrm{~mm}$ 

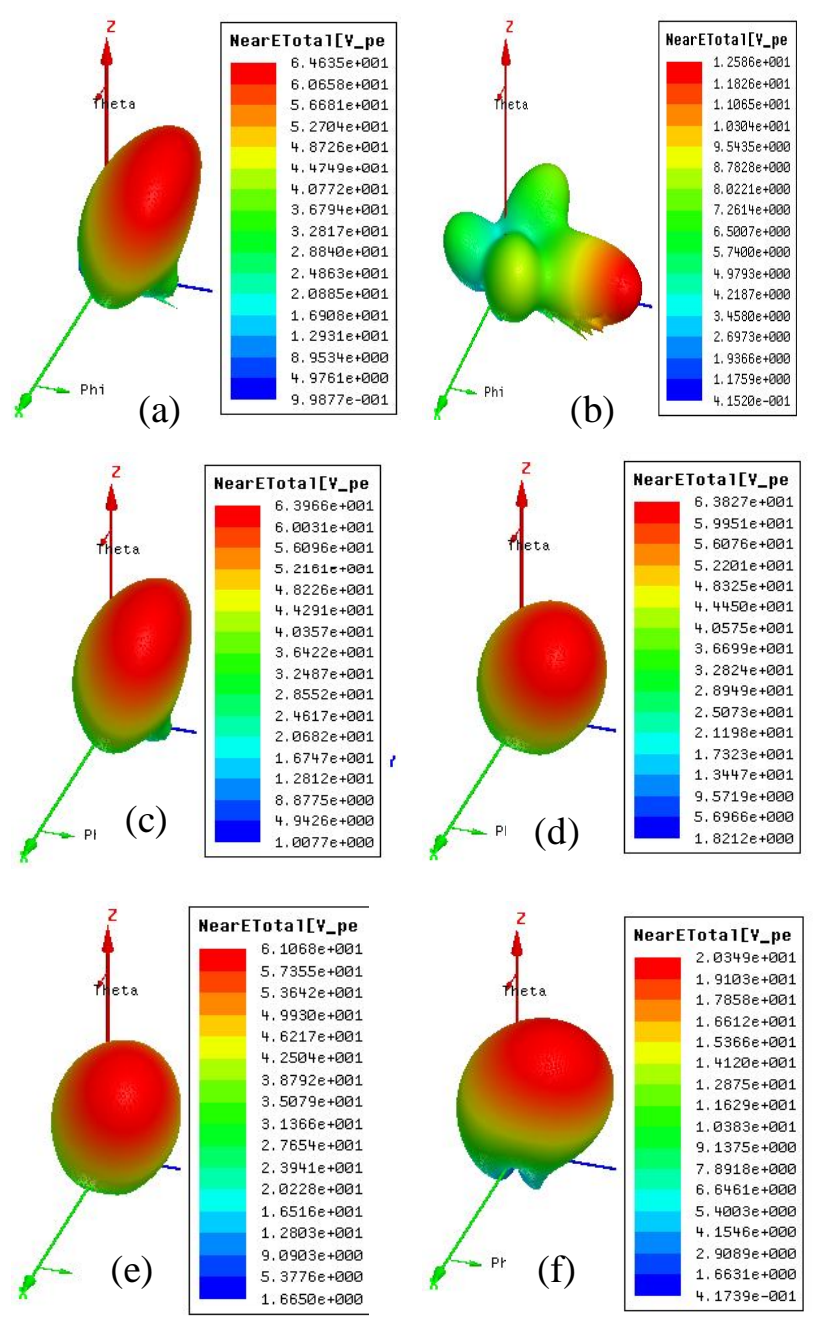

Figure 13: Near field simulation results for various interelement distances: (a) $d=47 \mathrm{~mm}$, (b) $d=45 \mathrm{~mm}$, (c) $d=43 \mathrm{~mm}$, (d) $d=31 \mathrm{~mm}$, (e) $d=29 \mathrm{~mm}$, (f) $d=27 \mathrm{~mm}$

The disappearance of the secondary lobes follows a condition on the separation of the elementary elements of the antenna:

$$
d<\frac{\lambda}{1+|\cos \theta|}
$$

This condition leads to not spacing the antennas by more than one wavelength. It tends to bring antennas as close as possible. However, the closer they are, the closer the couplings in the near field between antennas (Figure 13). However, these will change the characteristics of each antenna. There is therefore a compromise on the separation distance to be found between canceling the side lobes and reducing the coupling between antennas.

\section{CONCLUSION}

In this article, we have study and designed a new network antenna structure. The patch $\mathrm{H}$ with slot and parasitic element was used as basic element of our proposed antenna. The simulation results obtained after an optimal geometrical dimensioning of the supply network $1 \times 4$, using the HFSS software, are very good and meet the desired requirements. These results show that the reflection coefficient $S_{11}$ is of the order of $-31 \mathrm{~dB}$ at the resonance frequency, that the standing wave ratio of the proposed antenna is $<1.5$ in the frequency band [2.432-2.457] $\mathrm{GHz}$ and that the antenna has a gain of the order of $6.6 \mathrm{~dB}$. The bandwidth of the antenna is of a width of the order of $66 \mathrm{MHz}$ to $-10 \mathrm{~dB}$, therefore the antenna is selective.

\section{REFERENCES}

1. A. Bendali, M. Habibi, S. Bri, and A. Elfadl, "Improvement Of Rectangular Patch Antenna Performance For Rfid Applications.," J. Theor. Appl. Inf. Technol., vol. 74, no. 1, 2015.

2. P. F. Combes, Micro-ondes: Circuits passifs, propagation, antennes: cours et exercices. Dunod, 1997.

3. O. Picon, L. Cirio, C. Ripoll, G. Baudoin, J.-F. Bercher, and M. Villegas, Les antennes: Théorie, conception et applications. Dunod, 2009.

4. Khaled Mofawiz Alfawaz, Ezzelden Ibrahim Mohammed Ibrahim, "The Role of Information and Communications Technology (ICT) in Developing English Language Teaching from Teacher's Perspective," International Journal of Emerging Trends in Engineering Research, vol. 8, pp. 62-73, 2018.

5. M. A. Soliman, T. E. Taha, W. Swelam, and A. M. Gomaa, "3. 5/5 GHz Dual-Band 8 X 8 Adaptive Array Antenna," Prog. Electromagn. Res., vol. 34, pp. 85-98, 2013. https://doi.org/10.2528/PIERC12081513

6. Z. Yongxiang, C. Jianjun, S. Xuerui, and C. Hongxi, "The design study of the wide bandwidth and high gain RFID microstrip patch antenna," in Intelligent System Design and Engineering Applications (ISDEA), 2013 Third International Conference on, 2013, pp. 14201422 .

https://doi.org/10.1109/ISDEA.2012.338

7. A. S. M. Alqadami et al., "Multi-band antenna array based on double negative metamaterial for multi automotive applications," Prog. Electromagn. Res., vol. 159, pp. 27-37, 2017. https://doi.org/10.2528/PIER16091203

8. N. Mishra and R. K. Chaudhary, "A compact CPW fed CRR loaded four element metamaterial array antenna for wireless application," Prog. Electromagn. Res., vol. 159, pp. 15-26, 2017. https://doi.org/10.2528/PIER17021304

9. A. El Alami and S. D. Bennani, "Study Design and Optimization of a New Structure of Patch Antenna Linear Array for RFID Applications," WSEAS Trans. Commun., vol. 14, pp. 26-32, 2015.

10. A. El Alami and S. D. Bennani, "Design and simulation of RFID adaptive antenna array usign microstrip technology for object detection system," in Information Technology for Organizations Development (IT4OD), 2016 International Conference on, 2016, pp. 1-5. https://doi.org/10.1109/IT4OD.2016.7479268

11. O. Picon and others, "Les Antennes," Théorie, Concept. Appl. Paris Dunod, 2009.

12. A. Fouque, "Contribution à la conception d'un récepteur mobile failble coût et faible consommation dans la bande $\mathrm{Ku}$ pour le standard DVB-S," Bordeaux $1,2012$.

13. S. Venkata Rama Rao, A. Mallikarjuna Prasad, Ch. Santhi Rani, "Antenna Array Pattern Nulling by Phase 
A.Bendali et al., International Journal of Emerging Trends in Engineering Research, 7(12), December 2019,805 - 811

Perturbations using ModifiedDifferential Evolution Algorithm," International Journal of Emerging Trends in Engineering Research,vol. 8 No. 9, pp. 256-262, 2019.

https://doi.org/10.30534/ijeter/2019/07792019
14. R. J. Mailloux, Phased array antenna handbook. Artech house, 2017.

15. R. C. Hansen, Phased array antennas, vol. 213. John Wiley \& Sons, 2009.

https://doi.org/10.1002/9780470529188 